\title{
IL-27 suppresses airway inflammation, hyperresponsiveness and remodeling via the STAT1 and STAT3 pathways in mice with allergic asthma
}

\author{
DEGAN LU ${ }^{1}$, JIAMENG LU ${ }^{2}$, XIAOQING JI ${ }^{3}$, YANBO JI ${ }^{1}$, ZEWEN ZHANG $^{4}$, \\ HAIYING PENG ${ }^{5}$, FEI SUN ${ }^{5}$ and CAIQING ZHANG $^{1}$
}

\begin{abstract}
${ }^{1}$ Department of Respiratory Medicine and Critical Care, Shandong Qianfoshan Hospital, Cheeloo College of Medicine, Shandong University, Jinan, Shandong 250014; ${ }^{2}$ Department of Biomedical Engineering, Jilin Medical College, Jilin 132013; ${ }^{3}$ Division of Disinfectant and Supply, Shandong Qianfoshan Hospital, Cheeloo College of Medicine, Shandong University, Jinan, Shandong 250014; ${ }^{4}$ Department of Magnetic Resonance, Shandong Medical Imaging Research Institute, Shandong University, Jinan, Shandong 250021; ${ }^{5}$ Faculty of Graduate, Shan Dong First Medical University, Jinan, Shandong 271016, P.R. China
\end{abstract}

Received February 28, 2020; Accepted May 7, 2020

DOI: $10.3892 /$ ijmm.2020.4622

\begin{abstract}
Type 2 cytokine-associated immunity may be involved in the pathogenesis of allergic asthma. Although interleukin 27 (IL-27) has been reported as an initiator and suppressor of T-helper 1 (Th1) and T-helper 2 (Th2) responses, respectively, its effects on the development of asthma remain unclear. In the present study, mice were induced and challenged with ovalbumin and received subsequent intranasal administration of IL-27. Total and differential cell counts were determined from Wright-Giemsa-stained cytospins, whereas the cytokine levels were detected using ELISA. In addition, the expression levels of signal transducer and activator of transcription (STAT) 1, STAT3, GATA-binding protein-3 (GATA3) and T-bet (T-box transcription factor) were analyzed in T cells by western blot analysis. Their corresponding mRNA expression levels were determined by quantitative PCR. Airway remodeling was assessed by conventional pathological techniques. The results indicated that intranasal administration of IL-27 ameliorated airway inflammation and hyperresponsiveness in an acute model of asthma. Furthermore, IL-27 prevented airway remodeling in a chronic model of asthma. Following administration of IL-27, the mRNA expression levels of STAT1 and T-bet were upregulated, while those of GATA3 were downregulated. Moreover, the phosphorylation levels of STAT1 and STAT3 were increased. Taken together,
\end{abstract}

Correspondence to: Professor Caiqing Zhang, Department of Respiratory Medicine and Critical Care, Shandong Qianfoshan Hospital, Cheeloo College of Medicine, Shandong University, 16766 Jingshi Road, Lixia, Jinan, Shandong 250014, P.R. China E-mail: freezcq66@163.com

Key words: asthma, interleukin 27, signal transducer and activator of transcription 1, signal transducer and activator of transcription 3 these findings demonstrated that intranasal administration of IL-27 ameliorated Th2-related allergic lung inflammation and remodeling in mouse models of asthma by repairing both the STAT1 and STAT3 pathways.

\section{Introduction}

Asthma is one of the most common chronic diseases and more than 300 million individuals worldwide currently suffer from asthma (1). It was estimated that the number will reach 400 million by 2025 (2). Asthma has been considered a heterogeneous disease that comprises different phenotypes and shares similar clinical manifestations and typical features of airway inflammation, airway hyperresponsiveness (AHR) and airway remodeling $(3,4)$. Although corticosteroids and bronchodilators can control disease symptoms $(5,6)$, asthma is not readily preventable or curable $(7,8)$. Therefore, it is necessary to identify early effective primary prevention and intervention strategies.

Interleukin 27 (IL-27) is a novel cytokine composed of the subunit p28 (IL-27p28) and Epstein Barr virus-induced gene 3 (9). This molecule is primarily produced by activated antigen-presenting cells and exhibits pleiotropic effects on T-helper cell responses $(9,10)$. For example, it induces T-helper 1 (Th1) cell differentiation $(11,12)$ and directly suppresses T-helper 2 (Th2) production and T-helper 17 (Th17) differentiation $(13,14)$. Th2-type cytokines play a pivotal role in airway inflammation and AHR, which are the hallmarks of asthma $(15,16)$. Therefore, IL-27 may play an important role in the pathogenesis of asthma.

Several studies have found that high levels of IL-27 combined with activation of the type- 2 signature are associated with increasing severity of asthma (17-19). IL-27 may be stimulated as a counter-regulatory cytokine to suppress Th2 inflammation (17-19). In addition, Miyazaki et al (20) reported that IL-27R (-/-) mice challenged with ovalbumin (OVA) exhibited increased asthmatic phenotypes, suggesting 
that IL-27 plays a pivotal role in the inhibition of lung inflammation and AHR. Jirmo et al (21) demonstrated that IL-27 is critical for the control of allergic asthma. Therefore, IL-27 is a novel, promising preventative agent for alleviating asthma development and exacerbation. A series of studies based on the OVA-induced mouse model have shown that preventative intranasal administration of IL-27 reduced airway inflammation and improved pathological changes, whereas IL-27 does not reduce airway inflammation and improve pathological changes when administered in a therapeutic mode following OVA challenge $(22,23)$. However, Yoshimoto et al (17) reported that intranasal administration of IL-27 could inhibit OVA-induced airway hyperresponsiveness and inflammation in OVA-immunized mice. The biological impact of IL-27 on asthma remains elusive and previous studies have shown contradictory pro-inflammatory and anti-inflammatory effects $(24,25)$. Furthermore, it has not been examined whether IL-27 plays a role in airway remodeling of chronic asthma.

In the present study, the effects of intranasal administration of IL-27 on airway inflammation and AHR were investigated in OVA-immunized mouse models of acute asthma. In addition, the effects of IL-27 on airway remodeling in mouse models of chronic asthma were explored. Finally, the effects of IL-27 stimulation on the expression levels of signal transducer and activator of transcription (STAT)1, STAT3, T-box transcription factor (T-bet), and GATA binding protein-3 GATA3) were studied. The data revealed that the effect of IL-27 was dependent on STAT1 and STAT3 pathways.

\section{Materials and methods}

Mice. A total of 24 healthy female BALB/c mice were purchased from the Experimental Animal Center of Shandong University and used between 6-8 weeks of age. The animals were kept under specific pathogen-free and standard conditions including $12 \mathrm{~h}$ light/dark cycle, room temperature of $22^{\circ} \mathrm{C}$, relative humidity of $60 \%$ and free access to food and water. The health and wellbeing of animals were monitored via daily observations of behaviour and condition. The mice were randomly assigned to three study groups: PBS group (PBS, $\mathrm{n}=8$ ), OVA group (OVA, $\mathrm{n}=8$ ) and IL-27 group (OVA + IL-27, $\mathrm{n}=8$ ). All procedures on mice were performed in accordance with the National Institutes of Health Guide for the Care and Use of Laboratory Animals (26). In addition, all protocols were approved by the Ethics Committee for Laboratory Animals Care and Use in Shandong Qianfoshan Hospital, Shandong University (Shandong, China).

Experimental model for OVA-induced acute asthma. OVA sensitization and challenge were accomplished using a modified protocol as previously described by Reddy et al (27) and Venkayya et al (16). Briefly, in the OVA and OVA + IL-27 groups, the mice received intraperitoneal (i.p.) injections containing $100 \mu \mathrm{g}$ OVA (Sigma-Aldrich; Merck KGaA), $2 \mathrm{mg}$ Alum (Thermo Fisher Scientific, Inc.) and $100 \mu \mathrm{l}$ PBS (Invitrogen; Thermo Fisher Scientific, Inc.) on days 0 and 7. The mice received aerosol challenge with $50 \mu \mathrm{l} \mathrm{PBS}$ and $100 \mu \mathrm{g}$ OVA intranasally (i.n.) on days 14-18 under light isoflurane anesthesia, which was performed for $1 \mathrm{~min}$ with a concentration of $3 \%$ isoflurane (28). The mice were sensitized with sterile endotoxin-free PBS/Alum and challenged with PBS i.n. on the same days in the PBS group. In the OVA + IL-27 group, the mice were treated i.n. with $50 \mu \mathrm{l}$ PBS and $50 \mathrm{ng}$ IL-27 twice a day on days 6 and 7. On days 0,7 and 14-18, the mice received i.n. $50 \mu \mathrm{l}$ PBS and $1 \mu \mathrm{g}$ IL-27 $1 \mathrm{~h}$ prior to OVA sensitization and the subsequent challenge. The mice were treated with $50 \mu \mathrm{l}$ PBS alone in the OVA and PBS groups (see the protocol scheme in Fig. 1A). Each group included eight mice.

Experimental model of OVA-induced chronic asthma. The mice were sensitized and challenged with OVA using a modified protocol described by Kirstein et al (29). In brief, a mixture containing $20 \mu \mathrm{g}$ OVA/1 mg Alum/200 $\mu \mathrm{l}$ PBS was delivered subcutaneously to mice on days $0,7,14$ and 21 to the OVA and OVA + IL-27 groups, while $1 \mathrm{mg}$ Alum/200 $\mu \mathrm{l}$ PBS was administered to the PBS group. On days 26 and 28 and on the following 4 weeks, the mice received i.n challenge of $20 \mathrm{mg}$ either OVA in PBS (50 $\mu \mathrm{l}$; OVA and OVA + IL-27 groups) or $50 \mu \mathrm{l}$ PBS alone (PBS group) following induction of anesthesia. The administration of OVA and IL-27 from day 28 was performed twice every week. In the OVA + IL-27 group, the mice were treated i.n. with $50 \mu \mathrm{l}$ PBS and $50 \mathrm{ng}$ IL-27 twice a day on days 6 and 7. On days $0,7,26-28,35,38,42,49$, 52, 56 and 59 the mice received i.n. $50 \mu$ PBS and 20 ng IL-27 $1 \mathrm{~h}$ prior to OVA sensitization and prior to the subsequent challenge. The mice were treated with $50 \mu \mathrm{l}$ PBS alone in the OVA and PBS groups (Fig. 2A). Each group included eight mice.

Measurement of airway responsiveness. Airway responses and dynamic lung compliance to methacholine challenge were assessed $24 \mathrm{~h}$ following the last OVA challenge, as previously reported (30). Briefly, the mice were anesthetized with pentobarbital sodium (50 mg/kg, i.p. injection) and the depth of anesthesia was determined by mice's responses to nociceptive stimulation and movement (31). No side effects of anesthesia were observed in 3 mice groups. After the mice were fully anaesthetized (immobility and absence of the withdrawal reflex of the right paw), a cannula was subsequently inserted into the trachea, and the mice were connected to the flexiVent system (Scireq). The mice were mechanically ventilated with a tidal volume of $5 \mathrm{ml} / \mathrm{kg}$ at a rate of $150 \mathrm{breaths} / \mathrm{min}$ with a positive end-expiratory pressure of $3 \mathrm{~cm} \mathrm{H}_{2} \mathrm{O}$ (32). In the plethysmograph chamber, a thermostat-controlled warming pad was built to retain the temperature at $37^{\circ} \mathrm{C}$. The mice were initially challenged with aerosol saline followed by challenge with increasing concentrations of acetyl- $\beta$-methylcholine chloride (methacholine; 0, 5, 10, and $20 \mathrm{mg} / \mathrm{ml}$; Sigma-Aldrich; Merck KGaA) for $10 \mathrm{sec}$ at each dose. Airway resistance and lung compliance were calculated as percentage increase over baseline (saline challenge).

Bronchoalveolar lavage (BAL). At $24 \mathrm{~h}$ following the final OVA challenge and immediately after the measurement of airway responsiveness, mice were euthanized by cervical dislocation and death was confirmed according to lack of breathing, pulse, corneal reflex and response to firm toe pinch (33). BAL fluid (BALF) was collected and processed as previously described (34). In brief, the trachea was cannulated and 4x1 ml PBS-EDTA (0.05 M; Merck KGaA) was instilled in the right lung and recovered by gentle manual aspiration. Subsequently, 

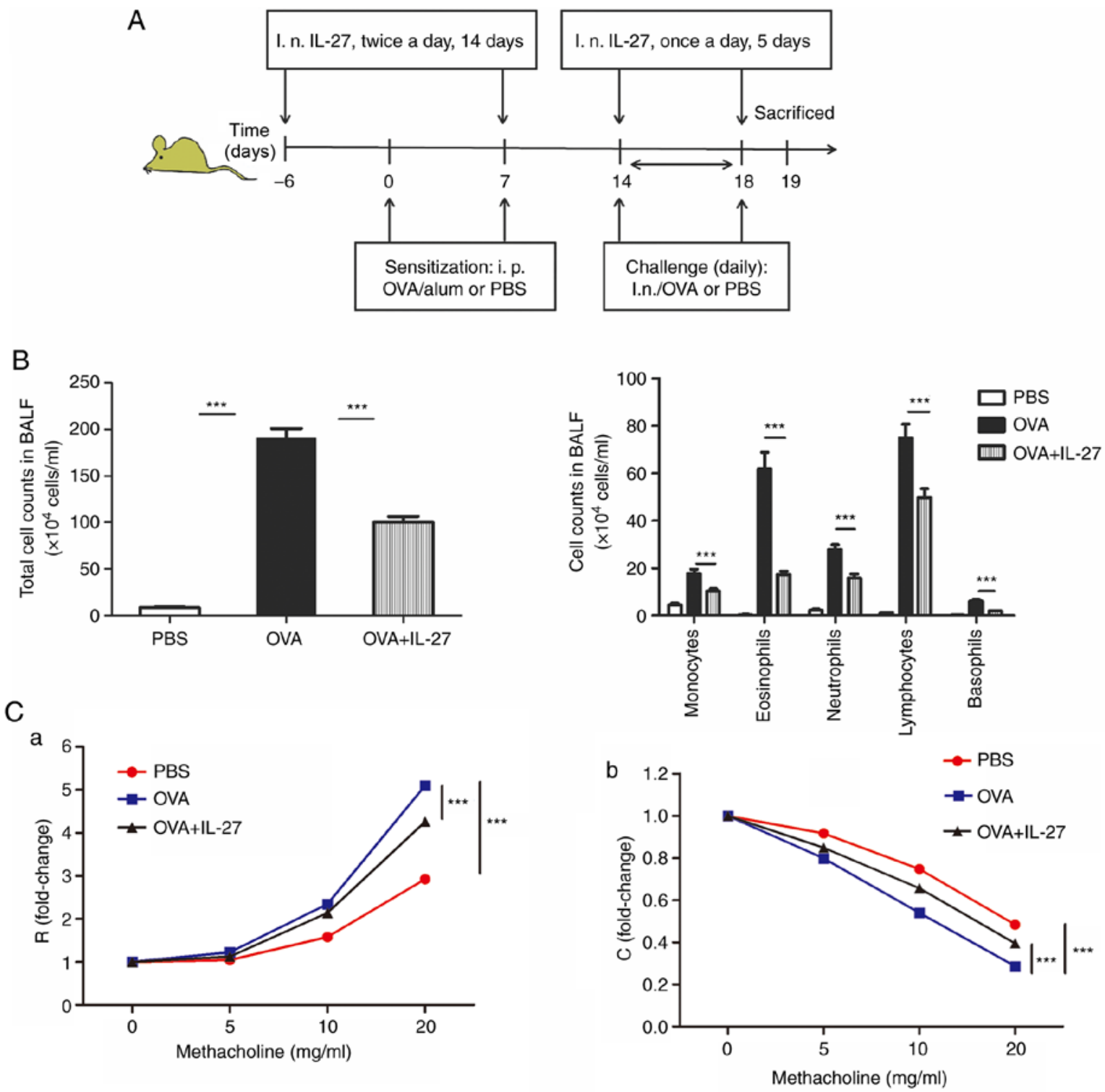

Figure 1. Intranasal administration of IL-27 alleviates airway inflammation and AHR in an acute model of experimental allergic asthma. (A) Protocol of OVA-induced allergic asthma and administration of IL-27. (B) The total cell number and the differential cell counts in the BALF samples. The total cell number and the numbers of macrophagocytes, neutrophil, basophils, eosinophils and lymphocytes were decreased in the OVA+IL-27 group. (C) AHR following methacholine challenge was measured in an invasive lung function assay. Treatment with IL-27 exhibited significant improvement in (a) lung resistance and (b) lung compliance. The data are expressed as the mean \pm standard error of the mean of three independent experiments, with eight animals per group. ${ }^{* * *} \mathrm{P}<0.001$. IL-27, interleukin 27; OVA, ovalbumin; AHR, airway hyperresponsiveness; BALF, bronchoalveolar lavage fluid; i.n, intranasal; R, lung resistance; $\mathrm{C}$, lung compliance.

the BALF was centrifuged $\left(80 \mathrm{xg}\right.$ for $10 \mathrm{~min}$ at $\left.4^{\circ} \mathrm{C}\right)$ and the cell pellets were resuspended in $1 \mathrm{ml}$ PBS-EDTA. Total and differential cell counts were determined on cytospin slide preparations and stained with Wright-Giemsa at room temperature for $8 \mathrm{~min}$. A total of 200 cells per slide were counted per sample using a light microscope at x400 magnification (DP73; Olympus Corporation) (35).

Enzyme-linked immunosorbent assay (ELISA). The expression levels of IL-4 (cat. no. M4000B), IL-5 (cat. no. M5000), IL-13 (cat. no. DY413), IL-17 (cat. no. M1700) and interferon (IFN)- $\gamma$ (cat. no. DY485) in the serum and supernatant of BALF were determined using ELISA kits (R\&D Systems, Inc.) as previously described, according to the manufacturer's protocol (36).
Reverse transcription-quantitative PCR (RT-qPCR). The left lungs of mice were removed immediately after collection of BALF and total RNA was extracted from the lung tissues using TRIzol ${ }^{\circledR}$ reagent (Invitrogen; Thermo Fisher Scientific, Inc.), according to the manufacturer's protocol. The concentration of RNA was assessed by a Nanodrop ${ }^{\mathrm{TM}}$ ND-1000 spectrophotometer (Thermo Fisher Scientific, Inc.). cDNA synthesis was performed using a Superscript III First-Strand Synthesis kit (Invitrogen; Thermo Fisher Scientific, Inc.), according to the manufacturer's protocols at $50^{\circ} \mathrm{C}$ for $50 \mathrm{~min}$. qPCR for mRNA detection was conducted using an ABI 7000 PCR instrument (Thermo Fisher Scientific, Inc.) according to the manufacturer's instructions. The PCR reaction system consisted of $1 \mu \mathrm{l}$ cDNA, $0.5 \mu \mathrm{l}$ of each forward and reverse primer, $10 \mu \mathrm{l}$ SYBR Green Mix (Beijing Solarbio Science \& Technology Co., Ltd.) 
A

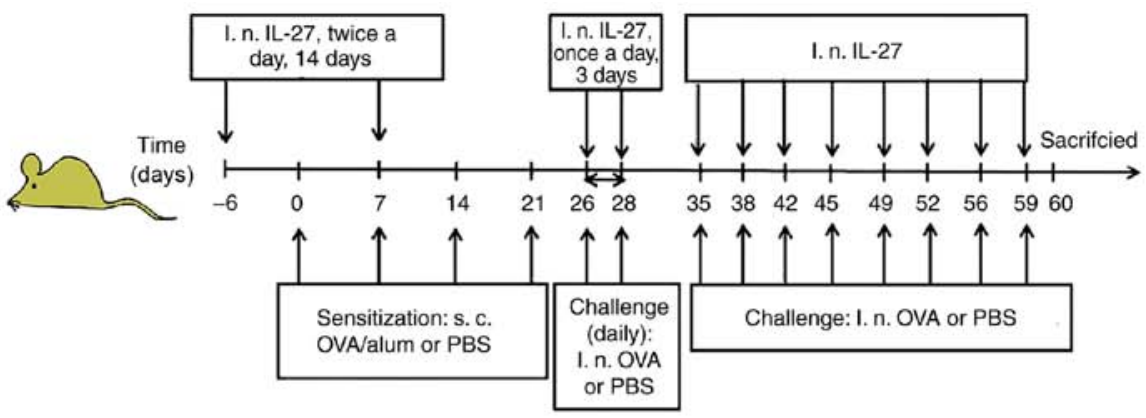

B

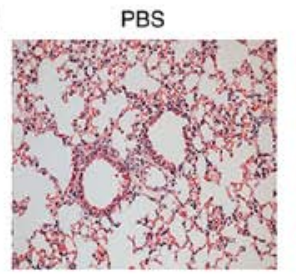

$\mathrm{C}$
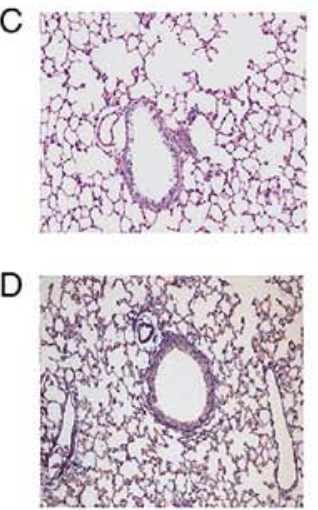

E

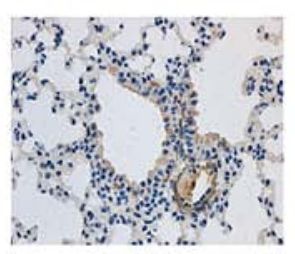

$\mathrm{F}$

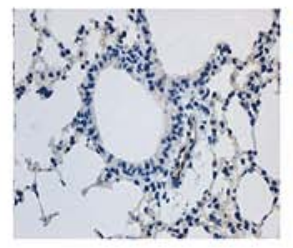

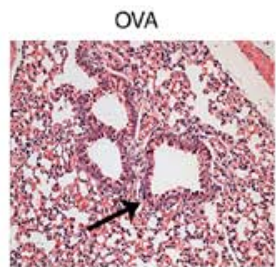
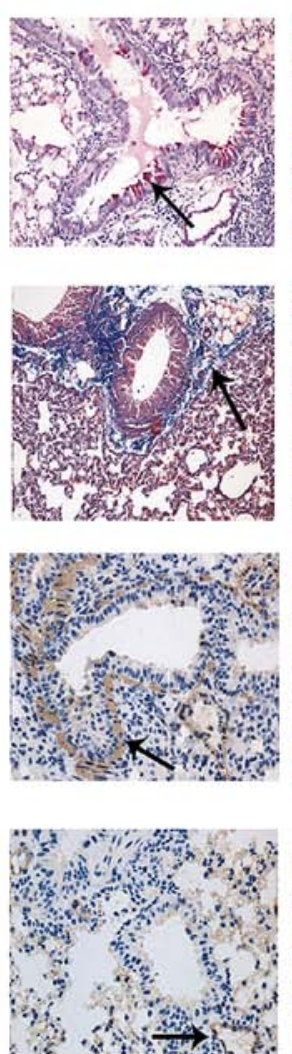

OVA+IL-27
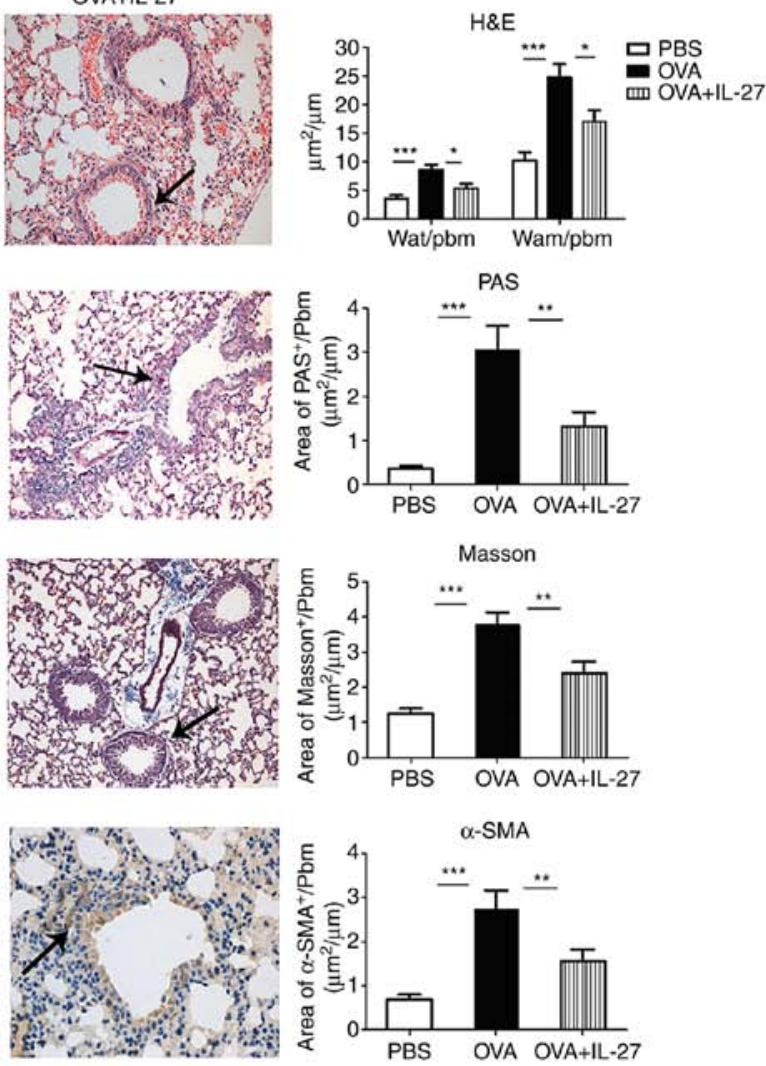

CD31
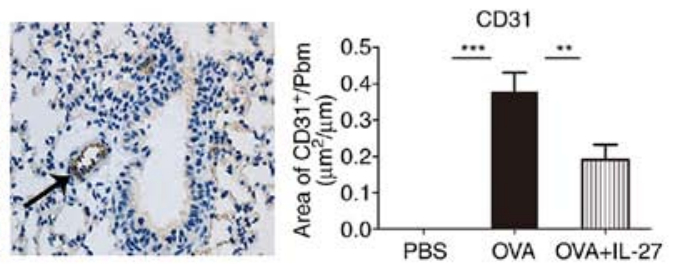

Figure 2. Intranasal administration of IL-27 prevents OVA-induced airway remodeling in a chronic experimental model of asthma. (A) Protocol of OVA-induced allergic asthma and administration of IL-27. (B) Representative photomicrographs of H\&E-stained lung sections from each group (x200 magnification). Significantly reduced basal membrane thickening and hyperplasia of airway smooth muscle cells (indicated by the arrow) were observed in IL-27-treated mice compared with OVA-exposed mice. (C) Representative photomicrographs of PAS-stained (indicated by the arrow) lung sections from each group (x200 magnification). Significantly reduced airway mucus production was observed in IL-27-treated mice compared with OVA-exposed mice. (D) Representative photomicrographs of Masson's trichrome-stained sections from each group (x200 magnification). Significantly reduced subepithelial fibrosis (indicated by the arrow) was observed in IL-27-treated mice compared with OVA-exposed mice. (E) Representative photomicrographs of $\alpha$-SMA-immunostained sections from each group (x400 magnification). Significantly reduced peribronchial $\alpha$-SMA-immunostained area (indicated by the arrow) was observed in IL-27-treated mice compared with the corresponding area from OVA-exposed mice. (F) Representative photomicrographs of CD31-immunostained sections from each group (x400 magnification). Significantly reduced peribronchial CD31-immunostained area (indicated by the arrow) was observed in IL-27-treated mice compared with the area of OVA-exposed mice. The data are expressed as the mean \pm standard error of the mean of three independent experiments with eight animals per group. ${ }^{*} \mathrm{P}<0.05,{ }^{* *} \mathrm{P}<0.01$ and ${ }^{* * *} \mathrm{P}<0.001$. IL-27, interleukin 27; OVA, ovalbumin; H\&E, hematoxylin and eosin; PAS, periodic-acid Schiff; $\alpha-$ SMA, $\alpha$-smooth muscle actin; Pbm, perimeter of basement membrane; Wat, total area of airway wall; Wam, area of smooth muscle; d, day; i.n, intranasal.

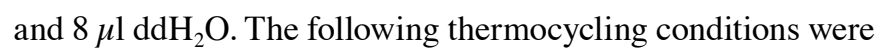
used for the qPCR: Initial denaturation at $94^{\circ} \mathrm{C}$ for $5 \mathrm{~min}$, followed by 40 cycles of $10 \mathrm{sec}$ at $94^{\circ} \mathrm{C}$ and $20 \mathrm{sec}$ at $60^{\circ} \mathrm{C}$ and a final extension of $30 \mathrm{sec}$ at $72^{\circ} \mathrm{C}$. $\beta$-actin was used as the reference control gene. The primer sequences used for this analysis and the expected size of the PCR products are listed 
Table I. Primer sequences used for reverse transcriptionquantitative PCR.

\begin{tabular}{llc}
\hline Gene & \multicolumn{1}{c}{ Sequence (5'-3') } & $\begin{array}{c}\text { Product } \\
\text { size (bp) }\end{array}$ \\
\hline STAT1 & $\begin{array}{l}\text { F: CACCCTTGCTTACTCTACTGC } \\
\text { R: TTGAATGACTAAACGCCTGA }\end{array}$ & 122 \\
STAT3 & $\begin{array}{l}\text { F: ACCTCCAGGACGACTTTG } \\
\text { R: AGGGCTGTGAGCATCTGT }\end{array}$ & 130 \\
GATA3 & $\begin{array}{l}\text { F: CCTTTATTCCTCCGTGTCTGC } \\
\text { R: ATCTTTGCGGGATAGTTAGC }\end{array}$ & 106 \\
T-bet & $\begin{array}{l}\text { F: TCCCATTCCTGTCCTTCACCG } \\
\text { R: ATGCTGCCTTCTGCCTTTCCA }\end{array}$ & 142 \\
& $\begin{array}{l}\text { F: CTGTGCCCATCTACGAGGGCTAT } \\
\text { R: TTTGATGTCACGCACGATTTCC }\end{array}$ & 155 \\
&
\end{tabular}

F, forward; R, reverse; STAT, signal transducer and activator of transcription; GATA3, GATA-binding protein-3; T-bet, T-box transcription factor; bp, base pair.

in Table I. The relative abundance of the mRNA transcripts was calculated using the $2^{-\Delta \Delta C q}$ method (37). Each sample was tested in triplicate and at least three wells were used for each group.

Western blot analysis. Western blot analysis was performed as described previously (38). Briefly, the proteins were extracted from mouse lung tissues and loaded on 5\% SDS polyacrylamide gels. A bicinchoninic acid protein assay kit (cat. no. 23225; Pierce; Thermo Fisher Scientific, Inc.) was used to determine protein concentration. Following electrophoresis, the proteins were transferred to PVDF membranes (EMD Millipore). The membranes were blocked in 5\% $(\mathrm{w} / \mathrm{v})$ nonfat dry milk in TBS-Tween-20 $(0.15 \%)$ at $37^{\circ} \mathrm{C}$ for $1 \mathrm{~h}$. Subsequently, membranes were incubated with primary antibodies against STAT1 (cat. no. sc-464), phosphorylated (p)-STAT1 (cat. no. sc-8394), STAT3 (cat. no. sc-482), p-STAT3 (cat. no. sc-8059), GATA3 (cat. no. sc-9009), T-bet (cat. no. sc-21003) and $\beta$-actin (cat. no. sc-47778; all from Santa Cruz Biotechnology, Inc.) separately. The dilutions of the primary antibodies were 1:500 and the incubations were performed overnight at $4^{\circ} \mathrm{C}$. Subsequently, the membranes were incubated with goat anti-rabbit immunoglobulin G-horseradish peroxidase secondary antibody (cat. no. sc-2004; 1:5,000; Santa Cruz Biotechnology, Inc.) at $37^{\circ} \mathrm{C}$ for $45 \mathrm{~min}$. $\beta$-actin was used as the internal control. The protein bands were visualized using an ECL detection reagent kit (GE Healthcare) according to the manufacturer's instructions. Densitometry was performed using Gel-Pro analyzer software (version 4.0; Media Cybernetics, Inc.).

Lung histology. The lung tissues (5- $\mu \mathrm{m}$ thick) were subsequently formalin-fixed and paraffin-embedded, as described previously (39). The lung sections were prepared and stained with hematoxylin and eosin (H\&E), Masson's trichrome and periodic acid-Schiff (PAS) stain according to a standard protocol $(39,40)$. Two pathologists who were blinded to the group assignment of mice independently evaluated and scored three differently stained tissue sections and the average scores were calculated. H\&E-stained lung sections were used mainly for the assessment of basal membrane thickening and hyperplasia of airway smooth muscle cells. Three bronchioles with 150-200 $\mu \mathrm{m}$ inner diameter were selected in each slide. The perimeter of basement membrane $(\mathrm{Pbm})$, total area of airway wall (Wat) and area of smooth muscle (Wam) were measured by morphometric analysis (Image-Pro Plus 6.0; Media Cybernetics, Inc.) and the ratios of Wat to $\mathrm{Pbm}$ (Wat/Pbm) and Wam to $\mathrm{Pbm}(\mathrm{Wam} / \mathrm{Pbm})$ were calculated (40). Masson's trichrome-stained sections were used to identify subepithelial fibrosis. The epithelial basement membranes with diameters of $>250 \mu \mathrm{m}$ were selected and both the collagen fiber area (stained in blue) beneath the basement membrane and $\mathrm{Pbm}$ were measured using Image-Pro Plus 6.0. The mean score of the fibrotic area divided by $\mathrm{Pbm}$ was calculated (41). PAS-stained sections were used for evaluating goblet cell hyperplasia. The bronchioles with 1.0-2.5 mm-long epithelial basement membranes were selected, and the area of goblet cells was measured as the area of PAS-positive staining using Image-Pro Plus 6.0. Subsequently, the ratio of the area of PAS-positive staining to $\mathrm{Pbm}$ was calculated (42). In addition, myofibroblast activation and angiogenesis were assessed by immunohistochemical analysis for $\alpha$-smooth muscle actin ( $\alpha$-SMA) (1:200; cat. no. sc-15320; Santa Cruz Biotechnology, Inc.) and CD31(1:100; cat. no. sc-28188; Santa Cruz Biotechnology, Inc.). The areas of peribronchial a-SMA-positive immunostaining and CD31-positive immunostaining in the sub-mucosa were outlined and determined by Image-Pro Plus 6.0 and the expression levels of these markers were quantified by the area of $\alpha$-SMA and CD31-positive staining relative to $\mathrm{Pbm}$ (43).

Statistical analysis. The data are expressed as the mean \pm SEM. Statistical analysis was performed using GraphPad Prism 5 software (GraphPad Software, Inc.). One-way ANOVA with Bonferroni's multiple comparisons test was used to determine statistical significance between experimental groups. $\mathrm{P}<0.05$ was considered to indicate a statistically significant difference.

\section{Results}

Intranasal administration of IL-27 alleviates allergic airway inflammation in an acute experimental model of asthma. The total cell number from BALF samples in the PBS group was significantly lower compared with the OVA group. Moreover, the total cell number in OVA + IL-27 group significantly decreased compared with the OVA group (Fig. 1B). Furthermore, the numbers of other inflammatory cells from BALF in the OVA+IL-27 group, such as macrophagocytes, lymphocytes, basophils and neutrophils, were also significantly reduced compared with the OVA group (Fig. 1B).

Intranasal administration of IL-27 ameliorates AHR in an acute experimental model of asthma. Baseline airway responsiveness (at $0 \mathrm{mg} / \mathrm{ml}$ methacholine) did not reveal significant differences among the three groups (Fig. 1C-a and C-b). In OVA-challenged mice, airway responsiveness $(\mathrm{R})$ to acetylcholine was significantly enhanced compared with that PBS-challenged mice (Fig. 1C-a). In the OVA + IL-27 group, 
IL-27 reversed methacholine-induced AHR as reflected by a significant reduction in airway resistance and a significant increase in lung compliance (C) compared with the OVA group (Fig. 1C-b).

Intranasal administration of IL-27 suppresses production of $I L-4, I L-5, I L-13$ and $I L-17$, whereas it induces $I F N-\gamma$ production in an acute experimental model of asthma. To determine whether IL-27 ameliorates inflammation and whether AHR can reflect altered cytokine profiles, the concentration levels of the latter markers were examined in both BALF and serum samples derived from mice. The OVA group exhibited significantly higher levels of $\mathrm{Th} 2$ cytokines (IL-4, IL-5 and IL-13) and the Th17 cytokine (IL-17), while significantly lower levels of the Th1 cytokine (IFN- $\gamma$ ) were observed compared with in the PBS group (Fig. 3). Compared with the OVA group, intranasal administration of IL-27 led to a significant reduction of IL-4, IL-5, IL-13 and IL-17, and a significant induction of IFN- $\gamma$ (Fig. 3).

Intranasal administration of IL-27 prevents OVA-induced airway remodeling in a chronic experimental model of asthma. To investigate whether IL-27 plays a role in the development of airway remodeling, airway epithelium, peribronchial interstitial tissue, airway smooth muscle cells and bronchial vasculature were used to evaluate IL-27 levels in a chronic experimental model of asthma. The representative sections of each group were stained with $\mathrm{H} \& \mathrm{E}$, Masson's trichrome and PAS, as well as with antibodies specific for $\alpha$-SMA and CD31 detection (Fig. 2). The OVA + IL-27 group exhibited significantly reduced peribronchial and perivascular inflammatory infiltrates, basal membrane thickening (Fig. 2B), mucus secretion (Fig. 2C), collagen deposition (Fig. 2D), number of airway smooth muscle cells (Fig. 2E) and vascular size (Fig. 2F) compared with the corresponding indices noted in the OVA group. Significant differences were noted for Wat/Pbm and Wam/Pbm (Fig. 2B), PAS area (Fig. 2C), Masson's trichrome (Fig. 2D), $\alpha$-SMA (Fig. 2E) and CD31-positive stained/Pbm (Fig. 2F) between PBS and OVA groups and OVA and OVA + IL-27 groups.

Intranasal administration of IL-27 in mice activates the STAT1 and STAT3 pathways. The involvement of the possible signaling pathways that include IL-27 was assessed. Both mRNA and protein levels of STAT1, STAT3, GATA3 and T-bet were detected in lung tissues using RT-qPCR and western blotting analyses. Compared with the OVA group, the mRNA expression levels of STAT1 were significantly upregulated in the OVA + IL-27 group while STAT3 levels exhibited no significant changes (Fig. 4A and B). Accordingly, the total and phosphorylated levels of STAT1 and STAT3 proteins and their ratios demonstrated similar changes (Fig. 5A and B). In addition, the mRNA and protein expression levels of GATA3 were increased in the OVA group compared with the PBS group, whereas these were reduced in the OVA+IL-27 group compared with the OVA group (Figs. $4 \mathrm{C}$ and $5 \mathrm{C}$ ). In contrast to these findings, compared with the PBS group, the expression levels of T-bet mRNA and protein were lower in the OVA group and higher in the OVA+IL-27 group compared with the OVA group (Figs. 4D and 5D).

\section{Discussion}

In the current study, the data indicated that intranasal administration of IL-27 significantly inhibited airway inflammation and AHR in the acute mouse models of experimental asthma. This finding is consistent with a study reported by Su et al (22) highlighting that preventative administration of IL-27 could reduce airway inflammation and improve AHR in asthmatic mice. In addition, the present study demonstrated that intranasal administration of IL-27 attenuated significant airway remodeling in chronic mouse models of experimental asthma. To the best of our knowledge, this is the only study which examined the effects of IL-27 on airway remodeling using a chronic asthma model. The data indicated that phosphorylation of STAT1 and STAT3 was impaired in the lung tissues of asthmatic mice and could be reversed by IL-27 administration.

As a pleiotropic cytokine, IL-27 is involved in the regulation of immune responses of certain inflammatory cells, such as $\mathrm{Th}$ cells, dendritic cells and macrophages (44). Therefore, IL-27 may be implicated in the pathogenesis of autoimmune and inflammatory diseases including asthma (45). Chronic airway inflammation is one of the main characteristics of asthma and plays a critical role in the pathogenesis of this disorder (46). Various types of cells, such as eosinophils, T cells, mast cells and neutrophils, are involved in the inflammatory response to allergens during asthma progression (20). AHR is one of the key features characteristic of asthma and one of the main factors responsible for the pathogenesis of this disease (47). AHR is characterized by increased airway resistance and decreased airway compliance (48). The results of the present study highlighted that intranasal administration of IL-27 could reduce inflammatory cell numbers in BALF samples and reverse methacholine-induced AHR. This indicated that IL-27 could effectively attenuate airway inflammation and AHR in experimental asthma. Furthermore, the serum and BALF concentration levels of the Th1 cytokines (IFN- $\gamma$ ) increased, whereas levels of Th2 cytokines (IL-4, IL-5, and IL-13) decreased in the OVA+IL-27 group compared with the OVA group, which suggested that enhanced production of Th2 cytokines and/or decreased production of Th1 cytokines may contribute to the effects of IL-27 on allergic asthma in this experimental model. These findings concur with a previous study, which demonstrated that preventative administration of IL-27 diminished BALF concentration levels of Th2 cytokines, such as IL-5 and IL-13 (22). IL-27 activates naive CD4+ $\mathrm{T}$ cells and natural killer (NK) cells to stimulate production of IFN- $\gamma$ (49). Moreover, it can upregulate the expression levels of IL-12Rb2 and T-bet to promote Th1-effector function (49). Both IFN- $\gamma$ and T-bet play a role in the suppression of AHR and eosinophil lung infiltration, indicating that IL-27 may have regulatory effects on asthmatic immune responses and promote the development of Th1 (50). In addition, IL-27 can directly suppress Th2 cell differentiation and conversely induce these cells to develop into Th1 cells that produce IFN- $\gamma$ (17). Under Th2 polarization conditions, naive IL-27 receptor WSX-1 ${ }^{-/-} \mathrm{CD} 4 \mathrm{~T}$ cells increased production of Th2 cytokines (14). Previous studies showed that certain cytokines, such as IL-4, IL-5 and IL-13, play important roles in the initiation of airway inflammation, AHR and in variable airflow obstruction $(15,51)$. Administration of IL-27 attenuated 
A

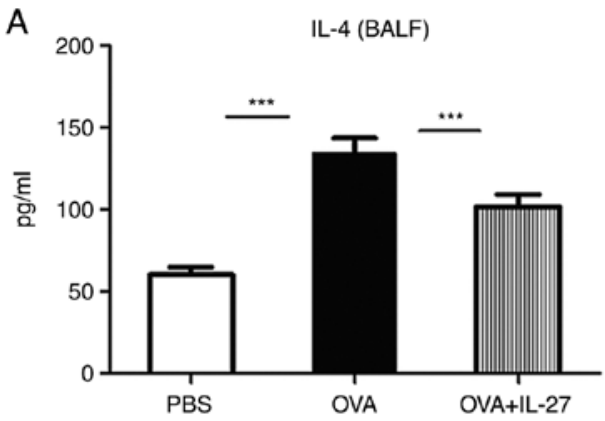

B

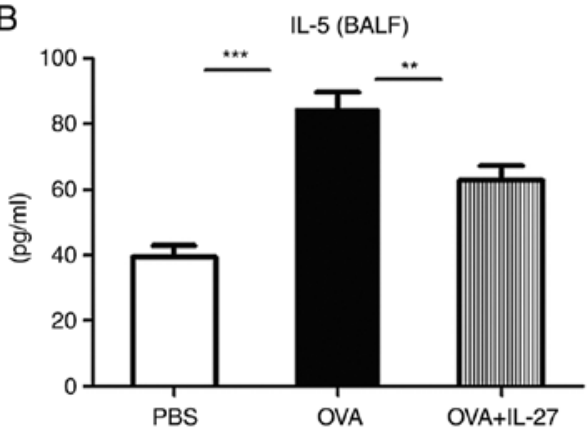

C

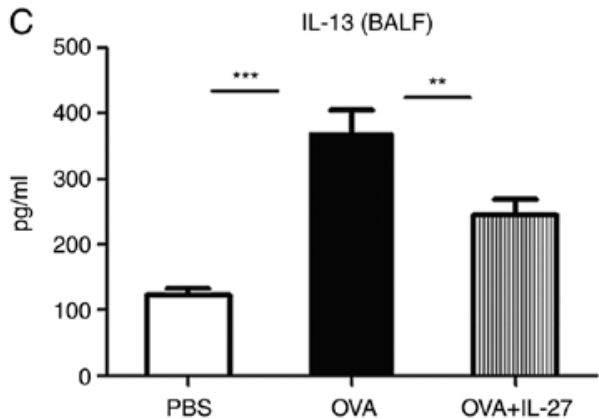

D

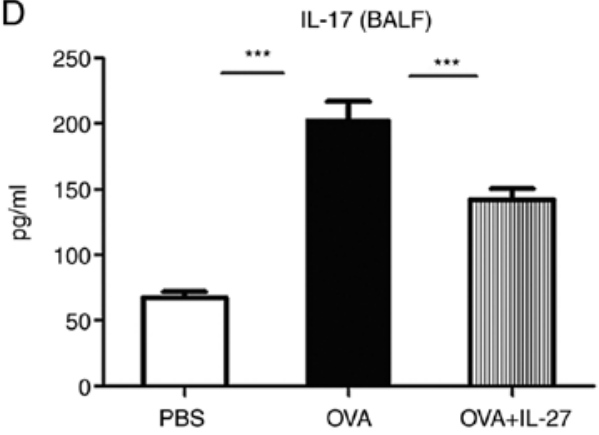

E

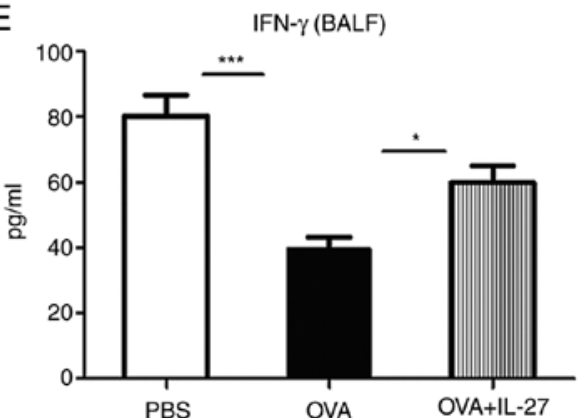

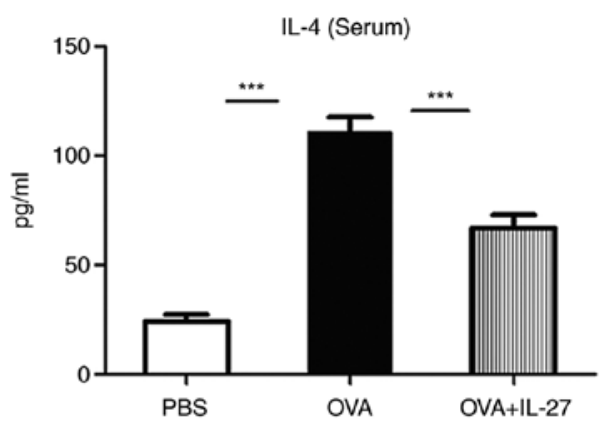
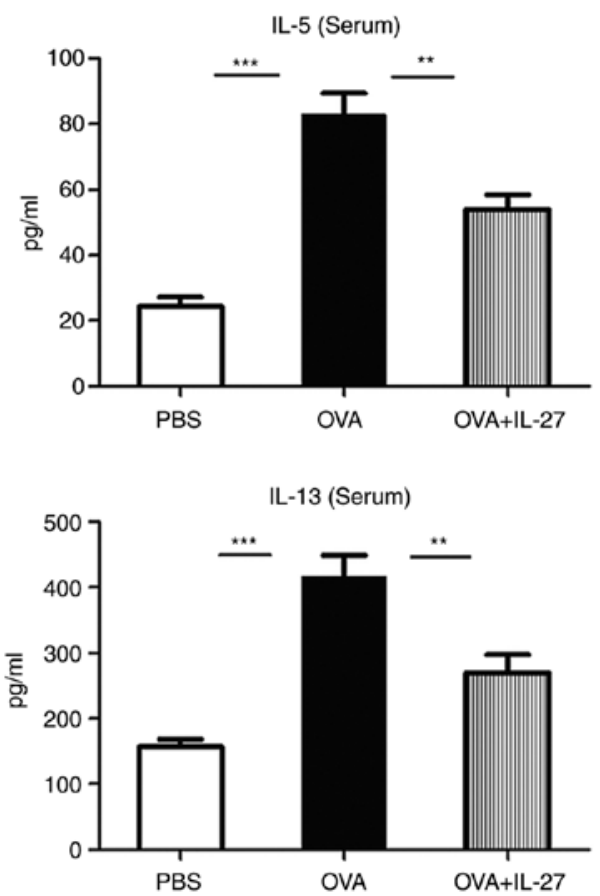

IL-17 (Serum)

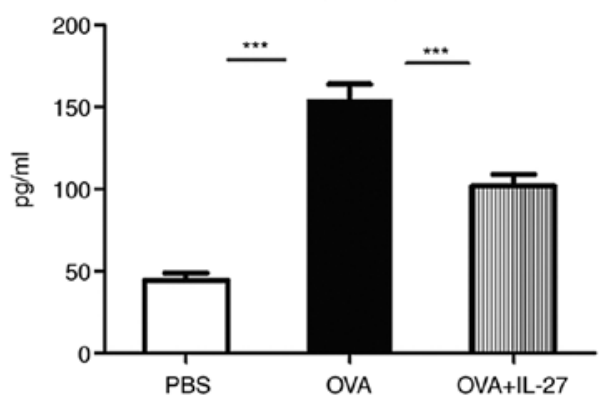

IFN- $\gamma($ Serum)

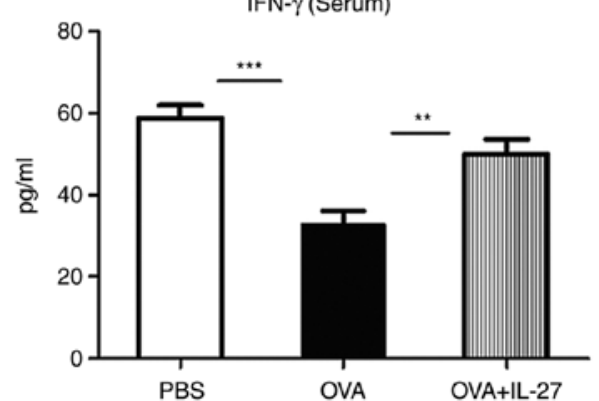

Figure 3. Intranasal administration of IL-27 reduces Th2 and Th17 cytokine levels and enhances the production of IFN- $\gamma$. The concentration levels of Th1, Th2 and Th17 cytokines in serum and BALF samples were measured by ELISA. The levels of (A) IL-4, (B) IL-5, (C) IL-13 and (D) IL-17 were lower, whereas those of (E) IFN- $\gamma$ were higher in the OVA+IL-27 group compared with the OVA group. The data are expressed as the mean \pm standard error of the mean of three independent experiments, with eight animals per group. ${ }^{*} \mathrm{P}<0.05,{ }^{* *} \mathrm{P}<0.01$ and ${ }^{* * *} \mathrm{P}<0.001$. IL, interleukin; Th, T-helper; BALF, bronchoalveolar lavage fluid; OVA, ovalbumin; IFN, interferon. 
A

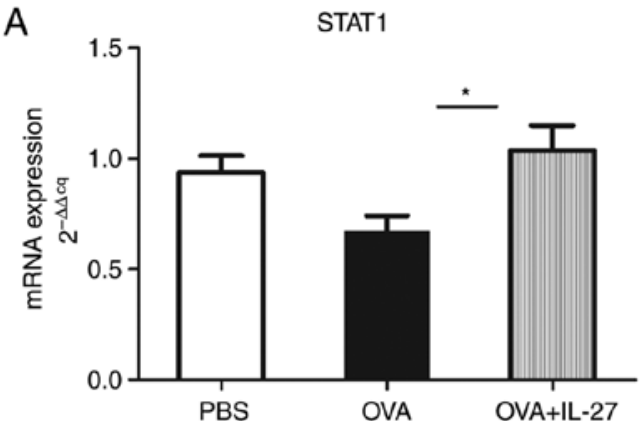

C

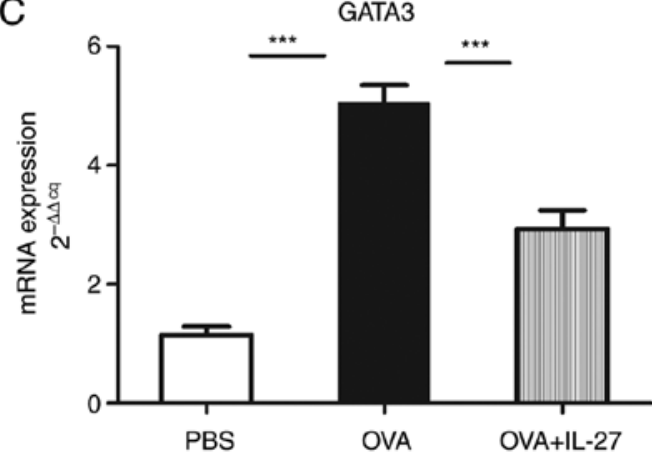

B

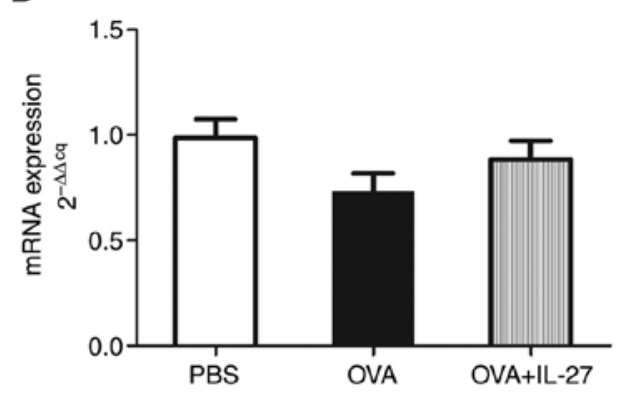

D

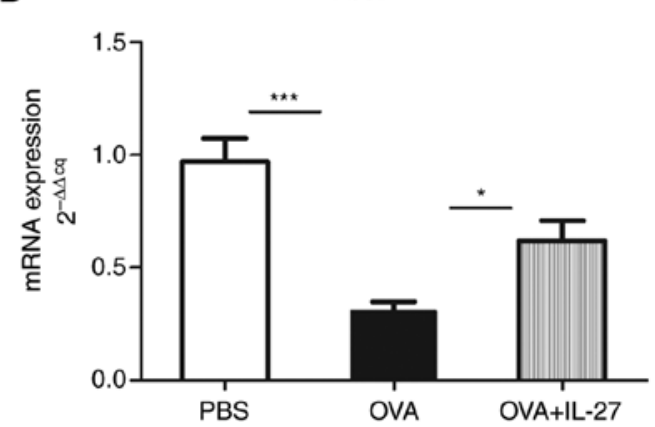

Figure 4. RT-qPCR analysis of intranasal administration of IL-27 in the acute model of asthma. The expression of (A) STAT1, (B) STAT3, (C) GATA3 and (D) T-bet mRNA in mouse lung tissues were evaluated by RT-qPCR. The graphs display a summary of two to three independent experiments. Data are expressed as the mean \pm standard error of the mean. ${ }^{*} \mathrm{P}<0.05$ and ${ }^{* * *} \mathrm{P}<0.001$. IL-27, interleukin 27; OVA, ovalbumin; STAT, signal transducer and activator of transcription; GATA3, GATA binding protein-3; T-bet, T-box transcription factor; RT-qPCR, reverse transcription-quantitative PCR.

allergen-induced AHR and airway inflammation, which are hallmarks of allergic asthma $(17,22,23)$. These studies are in concordance with the present work and demonstrated that IL-27 significantly suppresses Th2 cytokine production.

IL-17 is secreted by multiple cell types, such as Th17, NK cells, mast cells, neutrophils and $\gamma \delta$ T cells (52). IL-17 cytokines are also key players in several immune responses (52). Serum and BALF IL-17 levels were significantly downregulated in the OVA+IL-27 group compared with those noted in the OVA group. These findings suggested that IL-17 plays a role in allergic asthma and that IL-27 acts in a manner antagonistic to IL-17, which is in accordance with previously reported data $(21,53)$. Moreover, a previous study revealed that high levels of IL-17 were found in induced sputum and bronchial biopsies obtained from severe asthmatics and were associated with poor patient response to steroids (54). IL-27 inhibited the differentiation of Th17 cells by suppressing the expression of retinoic acid-related orphan receptor (ROR) $\gamma$ and ROR $\alpha$ (55). In addition, IL-27 has a direct effect on effector $\mathrm{T}$ cells and inhibited the development of IL-17-producing Th cells (56). Furthermore, IL-27 inhibited the expression of granulocyte-macrophage colony-stimulating factor, which is a regulator of Th17 cells (57).

Airway remodeling is a central feature of asthma (42). This condition includes epithelial changes, thickening of basement membrane, hypertrophy and hyperplasia of airway smooth muscle, angiogenesis, increased deposition of collagen proteins and subepithelial fibrosis (58). Airway remodeling is the main etiological factor of airflow limitation, bronchial hyperreactivity and mucus production (51). In the present study, it was initially shown that IL-27 could reduce the number of mucus-containing airway goblet cells (PAS-positive), the thickening of the basal membrane and the hyperplasia of airway smooth muscle cells. Previous studies have shown that in airway epithelial cells, both goblet cell hyperplasia and mucus overproduction can be induced by IL-13 $(59,60)$. In addition, certain Th2 cytokines exhibit a negative effect on epithelial hypertrophy in a murine model of asthma $(41,61)$. Therefore, IL-27 may modulate goblet cell proliferation, mucus production, and thickening of airway wall via a pathway including IL-13 and other cytokines.

Subsequently, subepithelial fibrosis was examined, which is an important feature of airway remodeling in asthma (62). The data indicated that OVA induced the activation of myofibroblasts (those expressing $\alpha$-SMA) in the experimental model of chronic asthma, whereas IL-27 inhibited this process. Furthermore, IL-27 decreased the area of Masson's-stained sections, which reflected reduced deposition of collagen, which is an ingredient of the extracellular matrix (ECM) (62). It was reported that higher numbers of fibroblasts are associated with severe asthma. The accumulation of peribronchial myofibroblasts was detected in a mouse model of chronic asthma $(63,64)$. Myofibroblasts and fibroblasts are the major sources of ECM proteins and deposition of the ECM, along with other components, such as fibronectin and glycoproteins, contributed to subepithelial fibrosis (62). IL-27 was found to suppress differentiation of myofibroblasts and fibroblasts and thereby alleviated the process of pulmonary fibrosis (65). Therefore, IL-27 may play a pivotal role in subepithelial fibrosis in the experimental model of chronic asthma.

Finally, the level of angiogenesis was assessed, and the vascular surface area was quantified by immunohistochemical 
A
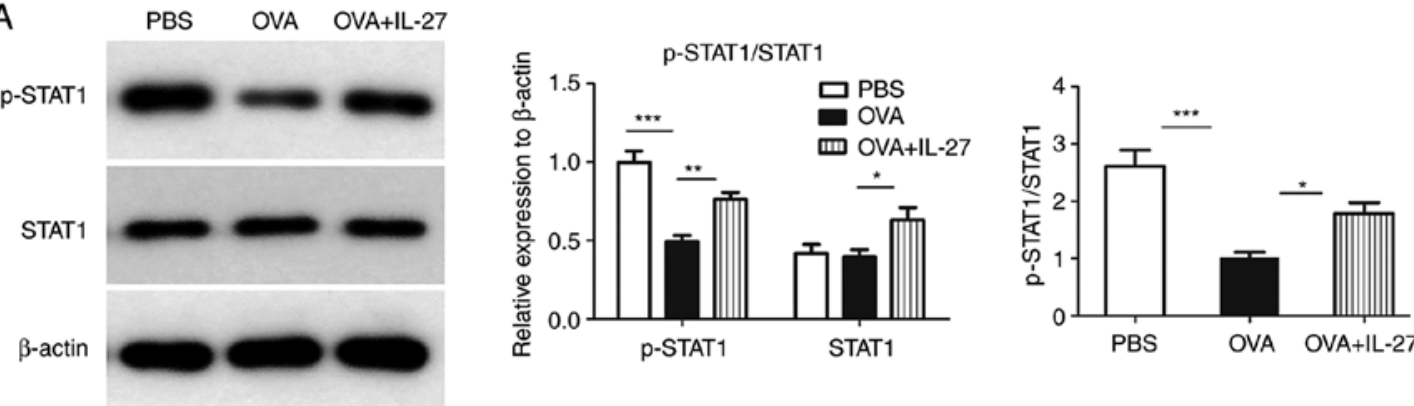

B

PBS OVA OVA+IL-27
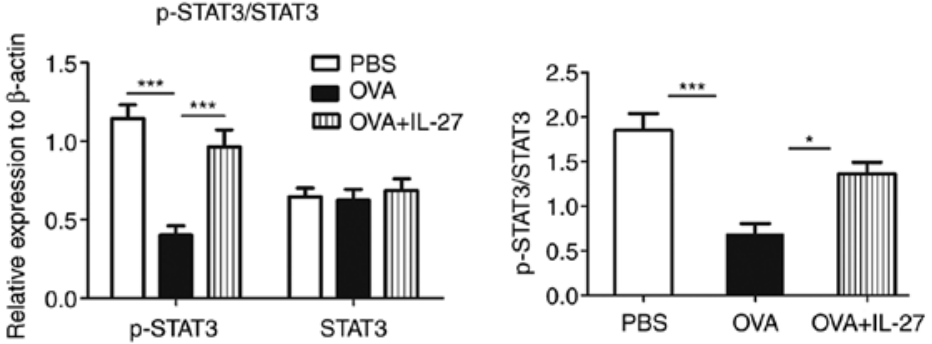

C
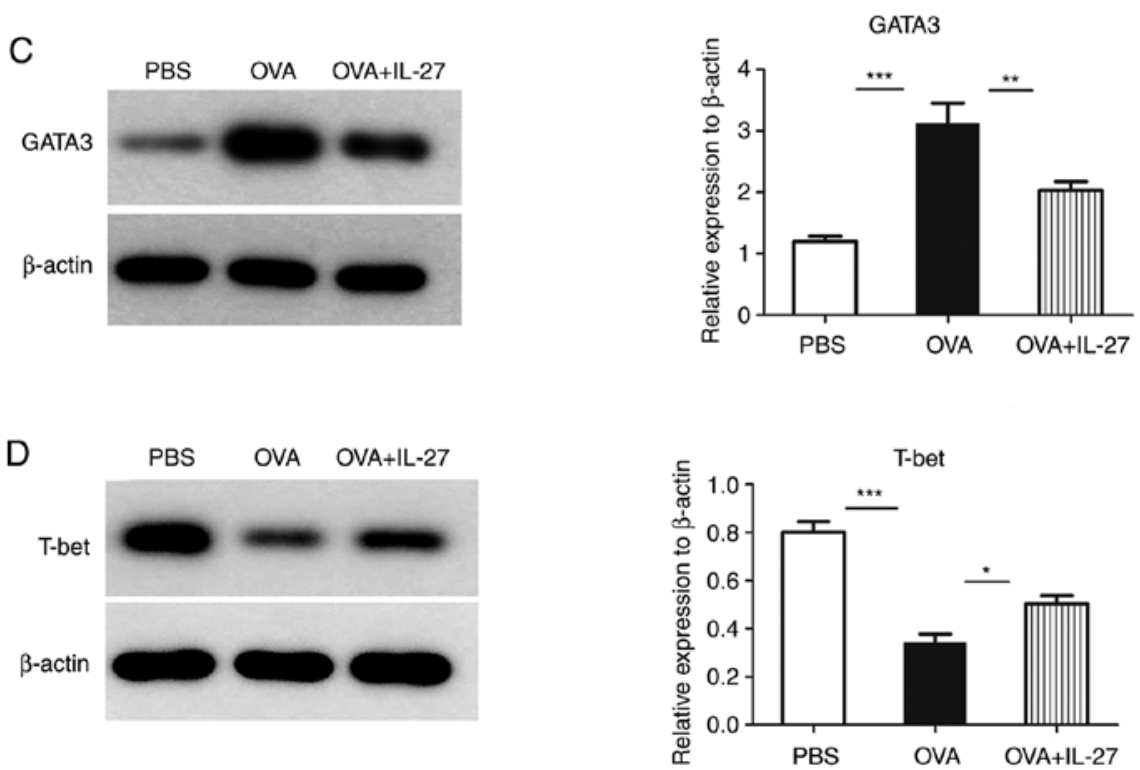

Figure 5. Western blot analysis of intranasal administration of IL-27 in the acute model of asthma. The protein expression levels of (A) p-STAT1 and STAT1 and (B) p-STAT3 and STAT3 and their ratios in mouse lung tissues were determined by western blot analysis. The protein expression levels of (C) GATA3 and (D) T-bet in mouse lung tissues were determined by western blot analysis. The graphs display a summary of two to three independent experiments. Data are expressed as the mean \pm standard error of the mean. ${ }^{*} \mathrm{P}<0.05,{ }^{* *} \mathrm{P}<0.01$ and ${ }^{* * *} \mathrm{P}<0.001$. IL-27, interleukin 27; OVA, ovalbumin; STAT, signal transducer and activator of transcription; GATA3, GATA binding protein-3; T-bet, T-box transcription factor; p, phosphorylated.

staining of CD31. Therefore, the extent of airway vascularity was increased in OVA-induced asthmatic mice compared with PBS-induced subjects. These data are consistent with previous reports $(66,67)$. Notably, the degree of angiogenesis was reduced in the OVA+IL-27 group. Lung inflammation may contribute to neovascularization and inflammation stimulated by effector cells, such as eosinophils, mast cells and macrophages, which are the major sources of various angiogenic and lymphangiogenic factors (66). Vascular endothelial growth factor (VEGF) may be an important player in the development of angiogenesis in asthma, whereas IL-27 can suppress both VEGFA mRNA expression and protein secretion (68). This suggested that IL-27 may control vascular remodeling. It was shown that IL-27 can inhibit angiogenesis in the tumor microenvironment in various malignancies such as prostate and lung cancer, which is a known anti-tumor mechanism (69). Taken together, the findings suggested that IL-27 can attenuate airway remodeling in a chronic mouse model of asthma.

It was that IL-27 can activate multiple signaling cascades, including Janus kinase (JAK) 1, JAK2 and tyrosine kinase-2 (70). STAT enzymes are the downstream proteins of JAKs (70). A previous in vitro study revealed that the effects of 
IL-27 on epithelial cells are dependent on STAT1 and STAT3 signaling pathways (71). IL-27 can exert its effects on T cells by inducing the phosphorylation of STAT1/STAT3/STAT5. In the current study, it was shown that both the STAT1 and STAT3 pathways were suppressed in the OVA group, whereas the opposite effects were noted in the OVA+IL-27 group, which indicated that the STAT1 and STAT3 pathways were impaired in the OVA-induced mice model of asthma. This impairment was reversed following IL-27 treatment. The STAT1 pathway is critically important for IL-27 signaling, which results in the induction of Th1 differentiation and the inhibition of Th2 differentiation (44). Following IL-27-stimulated activation of STAT1 signaling, the expression of T-bet was induced. T-bet serves as the main regulator of Th1 differentiation and of the expression of intercellular adhesion molecule 1 (ICAM-1)/lymphocyte function-associated antigen 1 (LFA-1) (12). The latter molecules interact and induce extracellular signal-regulated kinase activation (ERK) (67). ERK is located downstream of ICAM-1/LFA-1 and plays an important role in modulating the polarizing of naive T-helper cells toward Th1 subsets (12). Accordingly, IL-27 promotes early Th1 commitment by enhanced expression of IL-12R $\beta 2$ and production of IFN- $\gamma(12,72)$. Formation of the IL-12 receptor complex with IL-12 R $\beta 1$ and IL-12 R 32 leads to the cells response to IL-12, which is indispensable for Th1 initiation (72). In addition, IL-27 was reported to activate T-bet and lead to IFN- $\gamma$ secretion via the p38/mitogen-activated protein kinase signaling pathway, which is independent of JAK/STAT (11). Moreover, STAT1 is required for the suppression of the Th2-specific transcription factor, GATA-3 (73). In the presence of IL-2 and IL-4, naïve Th cells express GATA-3 at a high level and develop into Th2 cells (16). By suppressing GATA-3, IL-27 represses Th2 lineage commitment, which is dependent on STAT1 (73). Moreover, T-bet can directly interact with GATA-3, which interferes with the binding of GATA-3 to its target DNA, and causes inhibition of Th2 differentiation (74). In the present study, IL-27 upregulated T-bet expression and downregulated GATA-3 expression. These findings are in concordance with previous reports $(12,23)$.

In addition to STAT1 activation, IL-27 can increase STAT3 activation in naive CD4+T cells. Augmented activation of STAT3 is found to serve as a counterbalance to activation of STAT1 (18). The activation of STAT3 and STAT1 are reciprocally regulated and their balance in phosphorylation levels is key to maintaining appropriate immune responses (75). IL-27-induced activation of the STAT3 signaling pathway is important for proliferation and differentiation of T-cells (45,70). The expression levels of T-bet and GATA-3 can be modulated by STAT3 along with STAT1, leading to the positive or negative regulation of Th1 and Th2 differentiation (73). By activation of the STAT1 and STAT3 pathways, IL-27 also inhibited $\gamma \delta$ T cells from producing Th2-related cytokines, such as IL-5 and IL-13 (76) in the immune response against tumors. STAT3 activation further plays an important role in Th17 cell differentiation (77). Activated STAT3 directly binds to IL-17A and IL-17F promoters and increased IL-17 gene transcription (77). In addition to the activation of STAT3, the induction of ROR $\gamma \mathrm{t}$, a master regulator of Th17 cell differentiation, is required for the expression of genes encoding IL-17 in naïve CD4+ Th cells (78). IL-27 can modulate the activity of ROR $\gamma \mathrm{t}$ and plays an important role in the development of
Th17 cell differentiation (78). These findings are in alignment with the evidence of the present study, which indicated that the STAT1 and STAT3 pathways were suppressed in the OVA group and activated in the OVA+IL-27 group. This evidence demonstrated that IL-27 upregulated the phosphorylation of STAT1 and STAT3 proteins and restored the STAT1 and STAT3 signaling pathways in the asthma mouse model used.

In summary, the present study demonstrated that intranasal administration of IL-27 could alleviate airway inflammation and AHR by restored both the STAT1 and STAT3 pathways in an experimental mouse model. The present study provided additional evidence that IL-27 could ameliorate airway remodeling in mice with chronic allergen exposure in vivo. These findings will add insight into the multifaceted role of IL-27 in asthma. Additional studies are required to ensure the potential therapeutic applications of IL-27 in asthma. The exact mechanism of IL-27 in therapeutic action requires further investigation.

\section{Acknowledgments}

The authors thank Dr Xianchen Liu for critical appraisal of the manuscript.

\section{Funding}

No funding was received.

\section{Availability of data and materials}

The datasets used and/or analyzed during the present study are available from the corresponding author on reasonable request.

\section{Authors' contributions}

DL, JL and CZ contributed to the conception and design of the present research. ZZ, JL, XJ, HP and FS performed the experiments, collected and analyzed the data. JL, XJ and YJ supervised the methods of all the experiments. JL, ZZ, HP, $\mathrm{XJ}$ and FS wrote the initial draft of the manuscript. DL, JL, $\mathrm{XJ}$ and $\mathrm{YJ}$ revised the manuscript. CZ critically reviewed the article. All authors read and approved the final version of the manuscript.

\section{Ethics approval and consent to participate}

All protocols were approved by the Ethics Committee for Laboratory Animal Care and Use in Shandong Qianfoshan Hospital, Shandong University (approval no. 2019-S-306). All procedures on mice were performed in accordance with the National Institutes of Health Guide for the Care and Use of Laboratory Animals.

\section{Patient consent for publication}

Not applicable.

\section{Competing interests}

The authors declare that they have no competing interests. 


\section{References}

1. Godar M, Blanchetot C, de Haard H, Lambrecht BN and Brusselle G: Personalized medicine with biologics for severe type 2 asthma: Current status and future prospects. MAbs 10: $34-45,2018$

2. Dominguez-Ortega J, Phillips-Anglés E, Barranco P and Quirce S: Cost-effectiveness of asthma therapy: A comprehensive review. J Asthma 52: 529-537, 2015.

3. Eder W, Ege MJ and von Mutius E: The asthma epidemic. N Engl J Med 355: 2226-2235, 2006.

4. Wenzel SE: Asthma phenotypes: The evolution from clinical to molecular approaches. Nat Med 18: 716-725, 2012.

5. Barnes CB and Ulrik CS: Asthma and adherence to inhaled corticosteroids: Current status and future perspectives. Respir Car 60: 455-468, 2015.

6. Conner JB and Buck PO: Improving asthma management: The case for mandatory inclusion of dose counters on all rescue bronchodilators. J Asthma 50: 658-663, 2013

7. Szefler SJ: Advances in pediatric asthma in 2012: Moving toward asthma prevention. J Allergy Clin Immunol 131: 36-46, 2013.

8. Petronella SA and Conboy-Ellis K: Asthma epidemiology: Risk factors, case finding, and the role of asthma coalitions. Nurs Clin North Am 38: 725-735, 2003.

9. Pflanz S, Timans JC, Cheung J, Rosales R, Kanzler H, Gilbert J, Hibbert L, Churakova T, Travis M, Vaisberg E, et al: IL-27, a heterodimeric cytokine composed of EBI3 and p28 protein induces proliferation of naive $\mathrm{CD} 4^{+} \mathrm{T}$ cells. Immunity 16 : 779-790, 2002.

10. Hunter CA: New IL-12-family members: IL-23 and IL-27, cytokines with divergent functions. Nat Rev Immunol 5: 521-531, 2005.

11. Meka RR, Venkatesha SH,Dudics S, Acharya B and Moudgil KD: IL-27-induced modulation of autoimmunity and its therapeutic potential. Autoimmun Rev 14: 1131-1141, 2015.

12. Owaki T, Asakawa M, Fukai F, Mizuguchi J and Yoshimoto T: IL-27 induces Th1 differentiation via $\mathrm{p} 38 \mathrm{MAPK} / \mathrm{T}-\mathrm{bet}-\mathrm{and}$ intercellular adhesion Molecule-1/LFA-1/ERK1/2-dependent pathways. J Immunol 177: 7579-7587, 2006.

13. Wang RX, Yu CR, Mahdi RM and Egwuagu CE: Novel IL27p28/IL12p40 cytokine suppressed experimental autoimmune uveitis by inhibiting autoreactive Th1/Th17 cells and promoting expansion of regulatory T cells. J Biol Chem 287: 36012-36021, 2012.

14. Artis D, Villarino A, Silverman M, He W, Thornton EM, Mu S, Summer S, Covey TM, Huang E, Yoshida H, et al: The IL-27 receptor (WSX-1) is an inhibitor of innate and adaptive elements of type 2 immunity. J Immunol 173: 5626-5634, 2004

15. Wills-Karp M: Immunologic basis of antigen-induced airway hyperresponsiveness. Annu Rev Immunol 17: 255-281, 1999.

16. Venkayya R, Lam M, Willkom M, Grünig G, Corry DB and Erle DJ: The Th2 lymphocyte products IL- 4 and IL-13 rapidly induce airway hyperresponsiveness through direct effects on resident airway cells. Am J Respir Cell Mol Biol 26: 202-208, 2002.

17. Yoshimoto T, Yoshimoto T, Yasuda K, Mizuguchi J and Nakanishi K: IL-27 suppresses Th2 cell development and Th2 cytokines production from polarized Th2 cells: A novel therapeutic way for Th2-mediated allergic inflammation. J Immunol 179: 4415-4423, 2007.

18. Xie M, Mustovich AT, Jiang Y, Trudeau JB, Ray A, Ray P, Hu H, Holguin F, Freeman B and Wenzel SE: IL-27 and type 2 immunity in asthmatic patients: Association with severity, CXCL9, and signal transducer and activator of transcription signaling. J Allergy Clin Immunol 135: 386-394, 2015.

19. Fujita H, Teng A, Nozawa R, Takamoto-Matsui Y, KatagiriMatsumura H, Ikezawa Z and Ishii Y: Production of both IL-27 and IFN-gamma after the treatment with a ligand for invariant NK T cells is responsible for the suppression of Th2 response and allergic inflammation in a mouse experimental asthma model. J Immunol 183: 254-260, 2009.

20. Miyazaki Y, Inoue H, Matsumura M, Matsumoto K, Nakano T, Tsuda M, Hamano S, Yoshimura A and Yoshida H: Exacerbation of experimental allergic asthma by augmented Th2 responses in WSX-1-deficient mice. J Immunol 175: 2401-2407, 2005.

21. Jirmo AC, Daluege K, Happle C, Albrecht M, Dittrich AM, Busse M, Habener A, Skuljec J and Hansen G: IL-27 is essential for suppression of experimental allergic asthma by the TLR7/8 agonist R848 (Resiquimod). J Immunol 197: 4219-4227, 2016.
22. Su X, Pan J, Bai F, Yuan H, Dong N, Li D, Wang X and Chen Z: IL-27 attenuates airway inflammation in a mouse asthma model via the STAT1 and GADD45 $\gamma / \mathrm{p} 38$ MAPK pathways. J Transl Med 14: 283, 2016

23. Liu X, Li S, Jin J, Zhu T, Xu K, Liu C, Zeng Y, Mao R, Wang X and Chen $\mathrm{Z}$ : Preventative tracheal administration of interleukin-27 attenuates allergic asthma by improving the lung Th1 microenvironment. J Cell Physiol 234: 6642-6653, 2019.

24. Villarino AV, Huang E and Hunter CA: Understanding the pro- and anti-inflammatory properties of IL-27. J Immunol 173: 715-720, 2004

25. Hirase T, Hara H, Miyazaki Y, Ide N, Nishimoto-Hazuku A, Fujimoto H, Saris CJM, Yoshida H and Node K: Interleukin 27 inhibits atherosclerosis via immunoregulation of macrophages in mice. Am J Physiol Heart Circ Physiol 305: H420-H429, 2013.

26. Department of Health and Human Services: Guide for the care and use of laboratory animals. NIH Pub no 85-23, Washington, DC, 1985.

27. Reddy AT, Lakshmi SP and Reddy RC: Murine model of allergen induced asthma. J Vis Exp: e3771, 2012.

28. Harikrishnan VS, Hansen AK, Abelson KS and Sørensen DB: A comparison of various methods of blood sampling in mice and rats: Effects on animal welfare. Lab Anim 52: 253-264, 2018.

29. Kirstein F, Nieuwenhuizen NE, Jayakumar J, Horsnell WGC and Brombacher F: Role of IL-4 receptor alpha-positive CD4(+) $\mathrm{T}$ cells in chronic airway hyperresponsiveness. J Allergy Clin Immunol 137: 1852-1862 e9, 2016.

30. Hoymann HG: Lung function measurements in rodents in safety pharmacology studies. Front Pharmacol 3: 156, 2012.

31. Overmyer KA, Thonusin C, Qi NR, Burant CF and Evans CR: Impact of anesthesia and euthanasia on metabolomics of mammalian tissues: Studies in a C57BL/6J mouse model. PLoS One 10: e0117232, 2015

32. Martin TR, Gerard NP, Galli SJ and Drazen JM: Pulmonary responses to bronchoconstrictor agonists in the mouse. J Appl Physiol 64: 2318-2323, 1988.

33. Leary S, Underwood W, Anthony R, Cartner S, Corey D, Grandin T, Greenacre C, Gwaltney-Brant S, McCrackin MA, Meyer R, et al: AVMA guidelines for the euthanasia of animals: 2013 edition. Available at: https://www.avma.org/KB/Policies/Documents/euthanasia.pdf, 2013.

34. Cataldo DD, Tournoy KG, Vermaelen K, Munaut C, Foidart JM, Louis R, Noël A and Pauwels RA: Matrix metalloproteinase-9 deficiency impairs cellular infiltration and bronchial hyperresponsiveness during allergen-induced airway inflammation. Am J Pathol 161: 491-498, 2002

35. Polte T, Behrendt AK and Hansen G: Direct evidence for a critical role of CD30 in the development of allergic asthma. J Allergy Clin Immunol 118: 942-948, 2006.

36. Albrecht $M$, Chen HC, Preston-Hurlburt P, Ranney $P$, Hoymann HG, Maxeiner J, Staudt V, Taube C, Bottomly HK and Dittrich AM: T(H)17 cells mediate pulmonary collateral priming. J Allergy Clin Immunol 128: 168-177, 2011.

37. Livak KJ and Schmittgen TD: Analysis of relative gene expression data using real-time quantitative PCR and the 2 (-Delta Delta C(T)) method. Methods 25: 402-408, 2001.

38. Loke WS, Freeman A, Garthwaite L, Prazakova S, Park M, Hsu K, Thomas PS and Herbert C: T-bet and interleukin-27: Possible TH1 immunomodulators of sarcoidosis. Inflammopharmacology 23 : 283-290, 2015.

39. Kelly-Welch AE, Melo ME, Smith E, Ford AQ, Haudenschild C, Noben-Trauth $\mathrm{N}$ and Keegan AD: Complex role of the IL-4 receptor alpha in a murine model of airway inflammation: Expression of the IL-4 receptor alpha on nonlymphoid cells of bone marrow origin contributes to severity of inflammation. J Immunol 172: 4545-4555, 2004.

40. Tang X, Nian H, Li X, Yang Y, Wang X, Xu L, Shi H, Yang X and Liu R: Effects of the combined extracts of Herba Epimedii and Fructus Ligustrilucidi on airway remodeling in the asthmatic rats with the treatment of budesonide. BMC Complement Altern Med 17: 380, 2017

41. Komai M, Tanaka H, Masuda T, Nagao K, Ishizaki M, Sawada M and Nagai H: Role of Th2 responses in the development of allergen-induced airway remodelling in a murine model of allergic asthma. Br J Pharmacol 138: 912-920, 2003.

42. Kohan M, Breuer R and Berkman N: Osteopontin induces airway remodeling and lung fibroblast activation in a murine model of asthma. Am J Respir Cell Mol Biol 41: 290-296, 2009. 
43. Eifan AO, Orban NT, Jacobson MR and Durham SR: Severe persistent allergic rhinitis. Inflammation but no histologic features of structural upper airway remodeling. Am J Respir Crit Care Med 192: 1431-1439, 2015.

44. Iwasaki Y, Fujio K, Okamura T and Yamamoto K: Interleukin-27 in T cell immunity. Int J Mol Sci 16: 2851-2863, 2015.

45. Ma N, Fang Y, Xu R, Zhai B, Hou C, Wang X, Jiang Z, Wang L, Liu Q, Han G and Wang R: Ebi3 promotes T- and B-cell division and differentiation via STAT3. Mol Immunol 107: 61-70, 2019.

46. Hamid Q and Tulic M: Immunobiology of asthma. Annu Rev Physiol 71: 489-507, 2009.

47. O'Byrne PM and Inman MD: Airway hyperresponsiveness Chest 123 (3 Suppl): S411-S416, 2003.

48. Kaczka DW, Ingenito EP, Israel E and Lutchen KR: Airway and lung tissue mechanics in asthma. Effects of albuterol. Am J Respir Crit Care Med 159: 169-178, 1999.

49. Tait Wojno ED, Hunter CA and Stumhofer JS: The immunobiology of the interleukin-12 family: Room for discovery. Immunity 50: 851-870, 2019.

50. Tumes DJ, Papadopoulos M, Endo Y, Onodera A, Hirahara K and Nakayama T: Epigenetic regulation of T-helper cell differentiation, memory, and plasticity in allergic asthma. Immunol Rev 278: 8-19, 2017.

51. Jacobsen EA, Doyle AD, Colbert DC, Zellner KR, Protheroe CA LeSuer WE, Lee NA and Lee JJ: Differential activation of airway eosinophils induces IL-13-mediated allergic Th2 pulmonary responses in mice. Allergy 70: 1148-1159, 2015.

52. Pappu R, Ramirez-Carrozzi V and Sambandam A: The interleukin-17 cytokine family: Critical players in host defence and inflammatory diseases. Immunology 134: 8-16, 2011.

53. Vultaggio A, Nencini F, Pratesi S, Maggi L, Guarna A, Annunziato F, Romagnani S, Parronchi P and Maggi E: The TLR7 ligand 9-benzyl-2-butoxy-8-hydroxy adenine inhibits IL-17 response by eliciting IL-10 and IL-10-inducing cytokines. J Immunol 186: 4707-4715, 2011.

54. Chesné J, Braza F, Mahay G, Brouard S, Aronica M and Magnan A: IL-17 in severe asthma. Where do we stand? Am J Respir Crit Care Med 190: 1094-1101, 2014.

55. Diveu C, McGeachy MJ, Boniface K, Stumhofer JS, Sathe M Joyce-Shaikh B, Chen Y, Tato CM, McClanahan TK, de Waal Malefyt R, et al: IL-27 blocks RORc expression to inhibit lineage commitment of Th17 cells. J Immunol 182: 5748-5756, 2009.

56. Muallem G, Wagage S, Sun Y, DeLong JH, Valenzuela A Christian DA, Harms Pritchard G, Fang Q, Buza EL, Jain D, et al IL-27 limits type 2 immunopathology following Parainfluenza Virus infection. PLoS Pathog 13: e1006173, 2017.

57. Young A, Linehan E, Hams E, O'Hara Hall AC, McClurg A, Johnston JA, Hunter CA, Fallon PG and Fitzgerald DC: Cutting edge: Suppression of GM-CSF expression in murine and human T cells by IL-27. J Immunol 189: 2079-2083, 2012.

58. Russell RJ and Brightling C: Pathogenesis of asthma: Implications for precision medicine. Clin Sci (Lond) 131: 1723-1735, 2017

59. Tanabe T, Fujimoto K, Yasuo M, Tsushima K, Yoshida K, Ise H and Yamaya M: Modulation of mucus production by interleukin-13 receptor alpha2 in the human airway epithelium. Clin Exp Allergy 38: 122-134, 2008.

60. TanabeT andRubin BK: Airwaygobletcells secrete Pro-inflammatory cytokines, chemokines, and growth factors. Chest 149: 714-720, 2016.

61. Foster PS, Ming Y, Matthei KI, Young IG, Temelkovski J and Kumar RK: Dissociation of inflammatory and epithelial responses in a murine model of chronic asthma. Lab Invest 80: 655-662, 2000.

62. Fernandes DJ, Bonacci JV and Stewart AG: Extracellular matrix, integrins, and mesenchymal cell function in the airways. Curr Drug Targets 7: 567-577, 2006.

63. Benayoun L, Druilhe A, Dombret MC, Aubier M and Pretolani M: Airway structural alterations selectively associated with severe asthma. Am J Respir Crit Care Med 167: 1360-1368, 2003.
64. Miller M, Cho JY, McElwain K, McElwain S, Shim JY, Manni M, Baek JS and Broide DH: Corticosteroids prevent myofibroblast accumulation and airway remodeling in mice. Am J Physiol Lung Cell Mol Physiol 290: L162-169, 2006.

65. Dong Z, Zhao X, Tai W, Lei W, Wang Y, Li Z and Zhang T: IL-27 attenuates the TGF- $\beta 1$-induced proliferation, differentiation and collagen synthesis in lung fibroblasts. Life Sci 146 24-33, 2016.

66. Detoraki A, Granata F, Staibano S, Rossi FW, Marone G and Genovese A: Angiogenesis and lymphangiogenesis in bronchial asthma. Allergy 65: 946-958, 2010.

67. Hoshino M, Nakamura Y and Hamid QA: Gene expression of vascular endothelial growth factor and its receptors and angiogenesis in bronchial asthma. J Allergy Clin Immunol 107: 1034-1038, 2001

68. Zhang Q, da Cunha AP, Li S, Hao Q, Kainz V, Huang Q and Wu HY: IL-27 regulates HIF-1 $\alpha$-mediated VEGFA response in macrophages of diabetic retinopathy patients and healthy individuals. Cytokine 113: 238-247, 2019.

69. Di Carlo E, Sorrentino C, Zorzoli A, Di Meo S, Tupone MG, Ognio E, Mincione G and Airoldi I: The antitumor potential of Interleukin-27 in prostate cancer. Oncotarget 5: 10332-10341, 2014.

70. Kamiya S, Owaki T, Morishima N, Fukai F, Mizuguchi J and Yoshimoto T: An indispensable role for STAT1 in IL-27-induced T-bet expression but not proliferation of naive CD4+ T cells. J Immunol 173: 3871-3877, 2004.

71. Diegelmann J, Olszak T, Goke B, Blumberg RS and Brand S: A novel role for interleukin-27 (IL-27) as mediator of intestinal epithelial barrier protection mediated via differential signal transducer and activator of transcription (STAT) protein signaling and induction of antibacterial and anti-inflammatory proteins. J Biol Chem 287: 286-298, 2012

72. Takeda A, Hamano S, Yamanaka A, Hanada T, Ishibashi T, Mak TW, Yoshimura A and Yoshida H: Cutting edge: Role of IL-27/WSX-1 signaling for induction of T-bet through activation of STAT1 during initial Th1 commitment. J Immunol 170: 4886-4890, 2003.

73. Lucas S, Ghilardi N, Li J and de Sauvage FJ: IL-27 regulates IL-12 responsiveness of naive CD4+ T cells through Stat1-dependent and -independent mechanisms. Proc Natl Acad Sci USA 100: 15047-15052, 2003.

74. Hwang ES, Szabo SJ, Schwartzberg PL and Glimcher LH: $\mathrm{T}$ helper cell fate specified by kinase-mediated interaction of T-bet with GATA-3. Science 307: 430-433, 2005.

75. Regis G, Pensa S, Boselli D, Novelli F and Poli V: Ups and downs: The STAT1:STAT3 seesaw of Interferon and gp130 receptor signalling. Semin Cell Dev Biol 19: 351-359, 2008.

76. Morandi F, Prigione I and Airoldi I: Human TCR $\gamma \delta+$ T cells represent a novel target for IL-27 activity. Eur J Immunol 42: 1547-1552, 2012

77. Hwang ES: Transcriptional regulation of $\mathrm{T}$ helper 17 cell differentiation. Yonsei Med J 51: 484-491, 2010.

78. Ivanov II, McKenzie BS, Zhou L, Tadokoro CE, Lepelley A, Lafaille JJ, Cua DJ and Littman DR: The orphan nuclear receptor RORgammat directs the differentiation program of proinflammatory IL-17 $7^{+}$T helper cells. Cell 126: 1121-1133, 2006.

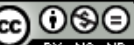

This work is licensed under a Creative Commons Attribution-NonCommercial-NoDerivatives 4.0 International (CC BY-NC-ND 4.0) License. 